\title{
Should Uniform Pricing Constraints be Imposed on Entrants?
}

\author{
Steffen Hoernig* \\ Universidade Nova de Lisboa; CEPR (London) \\ Travessa Estêvão Pinto \\ 1099-032 Lisboa \\ email: shoernig@fe.unl.pt
}

Version August 2002

\begin{abstract}
We analyse the effects of universal service obligations, such as uniform pricing, price caps and unbundling, on allocations in markets newly opened to competition, e.g. telecommunications. If uniform pricing is imposed not only on incumbents but also on entrants, entry may not result in competition if installed capacity is low, or may neglect high-cost areas if installed capacity or mandated coverage is high. These results hold no matter whether a price cap is in place or not, and do not depend on whether entry is capacity-based or facilitated through unbundling.

JEL classification: L43, L51, L52

Keywords: Universal Service Obligations, Uniform Pricing, Price caps, Unbundling, Entry
\end{abstract}

\footnotetext{
${ }^{*}$ We gratefully acknowledge partial financial assistance provided by the European Commission under the TMR network contract FMRX-CT98-0203. I would like to thank Bruno Jullien and seminar audiences at Universidade Nova de Lisboa, Pompeu Fabra, and ZEW Mannheim for helpful comments.
} 


\section{Introduction}

"Universal service obligations" (USOs) are common in the regulation of many industries such as telecommunications, postal services, public transport, electricity, water and gas supply (see e.g. Laffont and Tirole, 2000). They refer to restrictions imposed on state-owned monopolists or a designated firm, mostly now the privatized incumbent, in order to make the service accessible even for disfavored individuals or regions. These USOs have been strongly criticized as being the outcome of lobbying activities (originally from AT\&T, see Mueller 1997 and Crandall and Waverman 2000), rather than having been derived from economic principles. Whether or not they are justified on economic or political grounds, the fact is that USOs are in place in many countries and have real effects, not only on the welfare of consumers, but also on the outcome of competition and entry in the newly liberalized markets.

In this paper we therefore do not attempt to pronounce a judgment on USOs as such, but rather attempt to analyze some of their effects on market outcomes. A very common type of USOs are restrictions on pricing, in particular price caps, or uniform pricing (UP, or non-discrimination) constraints. It has been noted in the literature that a uniform pricing constraint makes the incumbent firm less aggressive (Armstrong and Vickers 1993, Anton et al. 2002, Choné et al. 2000, Valletti et al. 2002), which has the direct effect of making entry more attractive. Nevertheless, if one realizes that the incumbent will make his investment decisions taking into account any USOs imposed on him, it is possible that the entrant's market coverage (and total coverage) are smaller with the uniform pricing constraint than without (Valletti et al. 2002). Therefore the competitive effects of USOs are ambiguous.

A drawback to capacity-based entry (the entrant installs his own network) is that capacity is duplicated, which imposes additional costs. One way to achieve competition without duplication of capacity is "unbundling" of lines, where the entrant, instead of installing own lines, rents specific lines from the incumbents. We will consider both unbundling and capacity-based entry in relation to USO's.

An important determinant of future entry is the size of the incumbent before entry, i.e. his installed capacity. A high historic coverage is a strategical disadvantage for the incumbent firm, and entry will be more easily accommodated. On the other hand, if the incumbent has a small initial coverage, as for example in markets involving new services or technologies such as mobile telecommunications, competitive entry may be much more difficult. Therefore it will be necessary to analyze both cases in the following.

We will study the imposition of a UP constraint or a price cap on the 
entrant as well as on the incumbent. Without the UP constraint, the entrant could price discriminate between captive consumers, where the entrant is the only supplier, and non-captive consumers, where he competes with the incumbent. Both a uniform pricing constraint and a price cap limit the firms' opportunities to cash in on their captive consumers. In particular, the entrant may choose not only to compete with the incumbent for existing consumers, but may also invest in opening up hitherto unserved markets. In these markets the entrant does not face competition and can charge a high price. Therefore one might consider imposing a UP constraint on the entrant, too.

If installed capacity is small, our most surprising result is that imposing the UP constraint on the incumbent as well as on the entrant may be completely ineffective in that the resulting market allocation is identical to the outcome without entry. This constraint makes both firms less aggressive, and prompts the incumbent to locate himself in such a way that the entrant will not compete for his customers. In the end total coverage is the same as if no entry had occurred, and prices are equal to the price under monopoly.

On the other hand, imposing the UP constraint on the incumbent alone facilitates entry and leads the entrant to compete with the incumbent, resulting in lower prices not only for the customers served by both, but also for the captive customers of the incumbent. For this result to obtain it does not matter whether a price cap is imposed at the same time or not. The price cap simply limits what can be charged to customers, but does not change the strategic interaction between firms. ${ }^{1}$ This result shows that asymmetric regulation of firms can be preferable, in particular regulation that is only imposed on the dominant or incumbent firm.

As concerns unbundling, its effects are much more limited than one might expect. Unless uniform pricing is imposed solely on the incumbent, market allocations are identical. Unbundling with a UP constraint on the incumbent leads to higher utility than the monopoly allocation, but if UP is imposed on both firms then the same paradoxical result as above arises, i.e. the equilibrium allocation is identical to the monopoly allocation. Finally, if one compares welfare between unbundling and capacity-based entry under a UP constraint on the incumbent, the outcome depends on the value of the price cap.

If installed capacity is large at the outset, or if the incumbent is subject to a large mandated coverage, competitive entry will occur whether the UP constraint is imposed on both firms or not. The disadvantage of imposing

\footnotetext{
${ }^{1}$ If one assumes differentiated services instead of homogenous ones then a binding price cap does change the strategic interaction, see Valletti et al. (2002).
} 
UP constraints on both firms in this case is that high-cost areas may not be served by either firm.

The paper will proceed as follows: Section 2 introduces the model, and section 3 derives the pricing equilibrium. Section 4 discusses the determination of firms' coverage, and section 5 discusses welfare. Section 6 concludes, while all proofs are contained in the appendix.

\section{The Model}

There are two firms, the "incumbent" and the "entrant", both offering an identical product (for example telecommunications services), and there is a continuum $[0, \bar{x}]$ of local markets with identical demand, ordered by fixed cost of being served: Installing capacity in market $x \in[0, \bar{x}] \operatorname{costs} F x, F>0 .^{2}$ For simplicity assume that in each local market both firms have the same constant marginal cost $c \geq 0$. Each local market has the same demand function $Q(p)$ with choke-off price $0<\hat{p} \leq \infty$. It creates profits gross of entry costs of $R(p)=(p-c) Q(p)$ if $p$ is strictly smaller than the other firm's price, and $R(p) / 2$ if prices are equal. Let the monopoly price be $0<$ $p^{m}<\infty$ with monopoly profits $\pi^{m}>0$, and assume that $R(p)$ is continuous and strictly increasing on $\left[c, p^{m}\right]$. Under these assumptions all markets are identical once the fixed costs of entry are sunk, and therefore the only reason to price-discriminate between markets is that a firm is a monopolist in some markets while competing in others. That is, price-discrimination occurs only for strategic reasons.

We describe a price cap by a maximum price $p^{p c}>c$ which must not be exceeded by both firms. If there is no price cap imposed, define for simplicity $p^{p c}=p^{m}$. Let $\bar{p}=\min \left\{p^{p c}, p^{m}\right\}$, which is the maximum price that any firm might charge (no firm would ever want to exceed the monopoly price), and let $\bar{\pi}=R(\bar{p})$ be the corresponding local profit.

The model we consider has three stages. Given the USOs imposed by the regulator, in the first stage the "incumbent" determines which local markets he will cover. Coverage chosen cannot be lower than installed capacity but may well be higher. In the second stage, knowing the coverage of the incumbent and the USOs, the entrant chooses its coverage, while in the third stage firms compete in prices. This order of moves captures the fundamental difference between the incumbent and the entrant stemming from the incumbent's first-mover advantage.

\footnotetext{
${ }^{2}$ Qualitatively similar results can be obtained with other assumptions about declining net profitability of markets, for example decreasing population size.
} 
The equilibrium concept applied is that of subgame-perfect equilibrium, which means that at each stage the firms that make decisions foresee that both will choose equilibrium strategies in all following subgames. In particular, this means that they foresee that entry will only occur if it is profitable, and that entry will be accommodated when a price war endangers the incumbent's profits.

\section{$3 \quad$ Pricing equilibria}

In this section we will derive the equilibrium payoffs for the third stage of the game where firms set their prices simultaneously. At this stage location decisions and costs of entry are sunk. Relevant for pricing decisions are only the sizes of the areas of captive consumers, and of the area where firms compete. Furthermore, we do not need to treat the case of price caps separately, since we can subsume the cases with and without price caps by referring to the maximum price $\bar{p}$ defined above.

Even though firms have the same cost function, their strategic positions may differ. The firm with the larger captive market subject to a UP constraint is at a strategic disadvantage: It has the strongest incentive to charge a high price to cash in on its captive consumers. It becomes a softer competitor in the duopoly markets, where it loses customers, raising the profits of the other firm. This is the basic strategic mechanism underlying the economics of UP constraints (see the references mentioned above).

Let the firms compete in an area of size $D$, and let the size of each firm's captive market be $M_{I} \geq 0$ and $M_{E} \geq 0$. The outcome of competition depends decisively on whether zero, one, or two firms are subject to a uniform pricing constraint.

If no uniform pricing constraint is imposed, all markets are strategically independent, and firms compete in each as if it was the only one. Therefore, in a duopoly area the standard Bertrand equilibrium obtains with price equal to marginal cost, while in the monopoly areas the equilibrium price is $p^{*}=\bar{p}$. Profits without UP constraints are thus

$$
\Pi_{I}^{n}=\bar{\pi} M_{I}, \Pi_{E}^{n}=\bar{\pi} M_{E}
$$

To determine the equilibrium profits with UP constraints on the incumbent and possibly the entrant, we need the following lemma.

Lemma 1 Assume two firms $i=1,2$ producing a homogeneous good are competing in prices in a market of size $D \geq 0$, and each firm has a captive 
monopoly market of size $m_{i}$ subject to a UP constraint, i.e. the price charged by each firm in its captive market must be equal to its price in the duopoly market. Without loss of generality assume $m_{1} \geq m_{2} \geq 0$ and $m_{1}>0$. Then there is a unique (mixed) Nash equilibrium, with expected profits

$$
\Pi_{1}=m_{1} \bar{\pi}, \Pi_{2}=\frac{D+m_{2}}{D+m_{1}} m_{1} \bar{\pi} .
$$

Equilibrium prices follow distributions

$$
\begin{aligned}
& F_{1}(p)=\frac{D+m_{2}}{D}\left(1-\frac{m_{1}}{D+m_{1}} \frac{\bar{\pi}}{R(p)}\right) \\
& F_{2}(p)=\frac{D+m_{1}}{D}\left(1-\frac{m_{1}}{D+m_{1}} \frac{\bar{\pi}}{R(p)}\right)
\end{aligned}
$$

on $[p, \bar{p}]$, where $p$ is the unique price $p \in[c, \bar{p}]$ such that $R(p)=\bar{\pi} m_{1} /\left(D+m_{1}\right)$. Firm 1 plays $\bar{p}$ with probability. $\left(m_{1}-m_{2}\right) /\left(D+m_{1}\right)$.

Remarks: 1. The equilibrium collapses to the usual (pure) Bertrand equilibrium for $m_{1}, m_{2} \rightarrow 0$. For $m_{1}>0$ and $D>0$ no pure price Nash equilibrium exists, as can easily be verified. In equilibrium firms offer random discounts, and firm 1 sets the highest price $\bar{p}$ with probability $P=$ $\left(m_{1}-m_{2}\right) /\left(m_{1}+D\right)$. For $D=0$, i.e. when there is no market where firms 1 and 2 compete for clients, the unique (pure) equilibrium obviously involves both firms charging the maximum price $\bar{p}$ and making profits $m_{i} \bar{\pi}$, as can be seen from (2).

2. Firm 1's expected profits are equal to what he would gain if he was only serving his captive markets at the maximum price $\bar{p}$, while firm 2 makes profits strictly larger than its monopoly profits $m_{2} \bar{\pi}$ if both firms compete on an area $D>0$. This is the result of the strategic disadvantage of firm 1 mentioned above. In fact, firm 1 obtains the minimum payoff it can secure itself, i.e. it is "minmaxed". On the other hand, because of its strategic advantage firm 2 can secure itself higher profits, which are the larger the larger is $D$.

3. Lemma 1 only refers to captive markets that are subject to a UP constraint. Other captive markets not subject to this UP constraint are independent and do not influence pricing decisions in the previous set of markets. More precisely, in this paper we only consider the two cases where either all or none of a firm's captive markets are subject to the UP constraint.

4. If no price cap is imposed, then in (2) $\bar{\pi}=\pi^{m}$, otherwise $\bar{\pi}=\pi^{p c}$. Equilibrium prices will obviously depend on whether a price cap is imposed or not. The functional form of both profits and prices is the same, and, more 
importantly, the strategic effect of imposing a UP constraint is the same whether a price cap is imposed or not.

Let us now determine the profits under UP constraints. Assume first that only the incumbent is subject to a UP constraint, and both firms are subject to the same price cap. The entrant's captive market is not subject to the UP constraint, and the entrant sets price $\bar{p}$ in these markets. Then in the above notation we have $m_{1}=M_{I}, m_{2}=0$, and

$$
\Pi_{I}^{I}=M_{I} \bar{\pi}, \Pi_{E}^{I}=\left(\frac{D M_{I}}{D+M_{I}}+M_{E}\right) \bar{\pi}
$$

If on the other hand both firms are subject to the UP constraint and $M_{I} \geq$ $M_{E}$, then $m_{1}=M_{I}, m_{2}=M_{E}$ and

$$
\Pi_{I}^{I E}=M_{I} \bar{\pi}, \Pi_{E}^{I E}=\frac{D+M_{E}}{D+M_{I}} M_{I} \bar{\pi}
$$

It is interesting to note that in both cases the incumbent's expected profits are equal to monopoly profits in his captive area; clearly it does not matter for the incumbent whether the entrant's captive markets are subject to the UP constraint or not. In fact, the equilibrium distribution of the entrant's prices is the same in both cases, while the incumbent's prices are lower in the first case (in the sense of first order stochastic dominance, see appendix). Finally, the entrant's profits are higher if he is not subject to the UP constraint.

If $M_{E}>M_{I}$, then following the same reasoning, expected equilibrium profits are

$$
\Pi_{I}^{I E}=\frac{D+M_{I}}{D+M_{E}} M_{E} \bar{\pi}, \Pi_{E}^{I E}=M_{E} \bar{\pi}
$$

and the entrant is minmaxed because now he is the larger player and therefore at a strategic disadvantage.

Given the equilibrium profits in (1), (2) and (5) we can now determine both firms' coverage and location decisions.

\section{Equilibrium Allocations}

In this section we will show where firms will locate. Both firms make this decision being aware of which regulatory policies are imposed, and knowing that their location decisions determine how they will compete in the third stage. All they need to know at this stage are the expected gross profits (1), 
(4), (5) and (6) established in the previous section. A price cap $p^{p c}$ may be imposed or not, which we have subsumed in the definition of $\bar{\pi}$.

As a benchmark we derive the coverage that the incumbent would choose if there we no entry, and no (or sufficiently low) installed capacity. This benchmark provides us with an easier interpretation of the different scenarios under entry, and clarifies the workings of the model. If the incumbent covers the area $[0, x] \subset[0, \bar{x}]$, net profits are

$$
\hat{\Pi}^{m}=\int_{y=0}^{x}[(p(y)-c) Q(p(y))-F y] d y .
$$

Since under our assumptions firms only price-discriminate for strategic reasons, the incumbent will choose the same price in each market, and it does not matter whether a UP constraint is imposed or not. Furthermore, this price will be equal to $\bar{p}$ since there is no competitive pressure from entry. Therefore net profits become

$$
\hat{\Pi}^{m}=\int_{y=0}^{x}(\bar{\pi}-F y) d y=x \bar{\pi}-\frac{1}{2} F x^{2} .
$$

Maximum profits are obtained at $x$ such that local monopoly profits $\bar{\pi}$ are equal to the fixed costs of installation, $F x$. The resulting monopoly coverage is $x=x^{m}=\bar{\pi} / F$, which is increasing in $\bar{\pi}$. In particular, a lower price cap leads to a smaller coverage under monopoly because the fixed costs of serving the most expensive areas cannot be recovered. ${ }^{3}$ Let us summarize:

Proposition 1 If there is no entry, the coverage chosen by the incumbent monopolist is $X^{m}=\left[0, x^{m}\right]$ with $x^{m}=\bar{\pi} / F$, and net profits are $\Pi^{m}=\bar{\pi}^{2} / 2 F$. Coverage and net profits decrease with a lower price cap and higher entry cost, while it does not matter whether a uniform pricing constraint is imposed or not. In each market the price charged is the maximum price $\bar{p}$.

In the following we will first analyze the cases without unbundling, and treat unbundling in section 4.1. Large installed capacity will be considered in section 4.2. Until then we will assume that installed capacity of the incumbent is so low that it is less than the equilibrium coverage chosen by the incumbent; its value is then irrelevant. ${ }^{4}$

\footnotetext{
${ }^{3}$ In Valletti et al. (2002), we consider the effects of the introduction of minimum coverage constraints. These constraints avoid the loss in coverage, but for strategic reasons lead to higher prices under entry.

${ }^{4}$ It only impacts total profits because less capacity is to be installed, but does not change coverage decisions at the margin.
} 
We now examine equilibrium coverage if no UP constraint is imposed on either firm. In this case gross profits are given by (1) if the monopoly areas are $M_{I}$ and $M_{E}$, and both firms compete on an area of size $D$. The entrant makes zero profits in any local market where he attempts to compete with the incumbent, and on top of that would have to support the entry cost. Therefore, at stage two of this game, the entrant enters only in locations left vacant by the incumbent, and where he can recoup his fixed costs, i.e. only in vacant locations with $\bar{\pi} \geq F x$ or $x \leq x^{m}$. Going one step back to stage 1 , one remembers that $x \in\left[0, x^{m}\right]$ are precisely the locations that the incumbent would occupy as a monopolist. Given the fact that the entrant never enters a location if he is preempted by the incumbent, we see that the subgame-perfect equilibrium in this case is as follows:

Proposition 2 If no UP constraint is imposed on either of the firms, in equilibrium the incumbent chooses coverage $X^{n}=X^{m}$, and the entrant does not enter anywhere. ${ }^{5}$ Coverage and equilibrium prices are equal to the ones under monopoly.

This is a natural result given our assumptions that the entrant does not have lower costs of production ${ }^{6}$, and is at a strategic disadvantage due to the first-mover advantage of the incumbent. Therefore a "price umbrella" created by a UP constraint is necessary for the entrant to enter at all.

Let us now assume that a UP constraint is imposed on the incumbent only. Here the incumbent faces a basic trade-off: On the one hand, he would like to lower prices to be more competitive in the duopoly markets, and raise prices to cash in on his monopoly markets (e.g. see Armstrong and Vickers 1993). The entrant does not face this trade-off since he can pricediscriminate. He charges $\bar{p}$ in his monopoly area, and given monopoly areas $M_{I}, M_{E}$ and duopoly area $D$, gross profits are given by (4).

We will now determine what a subgame-perfect equilibrium of this game looks like. Let us first consider the entrant's choice at stage 2. Evidently, he will try to compete on a set of markets where fixed cost are low, depending on which markets the incumbent has occupied. Furthermore, he may be interested in entering into hitherto uncovered markets even if entry costs are high since there he does not face competition.

\footnotetext{
${ }^{5}$ Apart from $x=0$, where he is indifferent between entering or not. In general, all equilibria described in the following are unique up to changes on sets of measure zero.

${ }^{6}$ It is interesting to note that this no-entry result continues to hold for the area $X^{m}$ even if the entrant has lower costs of entry $F^{\prime}<F$. Here it would be efficient for the incumbent to cede all markets to the entrant, while in equilibrium the latter only covers the area $\left(x^{m}, \bar{\pi} / F^{\prime}\right]$.
} 
At stage 1, the incumbent must take into account that the entrant will compete in these markets. There he has basically two options: Install capacity even where he expects entry, or leave some of these markets vacant to limit exposure to competition. On the other hand, the fact that the entrant also covers the most expensive markets up to $x^{m}$ is of no strategic concern to him, since prices in these markets are independent of the ones practised where both firms compete. We find that in equilibrium the incumbent covers a whole interval $\left[0, x^{I}\right]$ with $x^{I}<x^{m}$, that is, he covers all the "cheap" markets. Three effects are at work in determining the attractiveness of reducing the duopoly area: First, there is some gain through higher prices in the remaining duopoly and monopoly markets since now the duopoly markets are relatively less important for the incumbent, which makes him price less aggressively. Second, there is the direct effect of profit loss due to not serving these markets. The third effect is more subtle: The reduction in duopoly area raises the marginal value of an additional duopoly location to the entrant. Therefore his reaction in the second stage is to invade some markets which previously were not of interest to him, bringing down prices and lowering profits of the incumbents. We show in the appendix that the second and third effects outweigh the first one.

The equilibrium outcome is described in the following proposition:

Proposition 3 If a UP constraint is imposed on the incumbent only, the incumbent chooses the coverage $X_{I}^{I}=\left[0, x^{I}\right]$ with $x^{I}=(\sqrt{3}-1) x^{m} \approx$ $0.732 x^{m}$. The entrant competes with the incumbent on $X_{E D}^{I}=\left[0, x^{D}\right]$ with $x^{D}=(2-\sqrt{3}) x^{m} \approx 0.268 x^{m}$, while serving the area $X_{E M}^{I}=\left(x^{I}, x^{m}\right]$ as a monopolist. Total coverage is equal to $X^{m}$. Expected gross profits are

$$
\begin{aligned}
\Pi_{I}^{I} & =\left(x^{I}-x^{D}\right) \bar{\pi}=(2 \sqrt{3}-3) \frac{\bar{\pi}^{2}}{F}, \\
\Pi_{E}^{I} & =\left(\frac{x^{D}\left(x^{I}-x^{D}\right)}{x^{I}}+\left(x^{m}-x^{I}\right)\right) \bar{\pi}=\frac{1}{2}(13-7 \sqrt{3}) \frac{\bar{\pi}^{2}}{F},
\end{aligned}
$$

while expected total profits are

$$
\begin{aligned}
\hat{\Pi}_{I}^{I} & =\Pi_{I}^{I}-\frac{1}{2} F\left(x^{I}\right)^{2}=(3 \sqrt{3}-5) \frac{\bar{\pi}^{2}}{F} \approx 0.392 \Pi^{m} \\
\hat{\Pi}_{E}^{I} & =\Pi_{E}^{I}-\frac{1}{2} F\left(\left(x^{D}\right)^{2}-\left(x^{I}\right)^{2}+\left(x^{m}\right)^{2}\right)=\frac{1}{2}(9-5 \sqrt{3}) \frac{\bar{\pi}^{2}}{F} \approx 0.340 \Pi^{m}
\end{aligned}
$$

Consumers are charged $p_{D}=\min \left\{p_{I}, p_{E}\right\}$ on $X_{E D}^{I}, p_{I}$ on $X_{I}^{I} \backslash X_{E D}^{I}$, and $\bar{p}$ with certainty on $X_{E M}^{I}$. In terms of first-order stochastic dominance, we 
have $p_{D}<p_{I}<\bar{p}$ (but $p_{I}=\bar{p}$ with probability $\left.\sqrt{3} /(1+\sqrt{3}) \approx 0.634\right) .{ }^{7}$

This result is interesting: The incumbent does not cover the highestcost areas because, being involved in competition with the entrant in lowcost areas and subject to a UP constraint, he prices lower than would be necessary to cover their fixed costs. Nevertheless, these areas are now served by the entrant, and therefore total coverage does not decrease (neither does it increase) compared to monopoly. On the other hand, prices have gone down in the areas still served by the incumbent, i.e. consumers in these areas have benefitted from entry and the ensuing competition. It is noteworthy that also the consumers that are only served by the incumbent are charged lower prices, even if these prices are not as low as the ones that duopoly consumers pay.

Now we turn to the case of imposing the UP constraint on both firms. The decisive difference to the previous case is that pricing in the entrant's monopoly area is not any more independent of what happens in the other markets. Given both firms' coverages, the entrant faces the same trade-off between lower prices to compete for the duopoly markets, and higher prices in his captive markets, which makes him a less aggressive competitor. More importantly, the entrant is willing to "exchange" duopoly markets for captive markets: If the incumbent leaves some additional, even high-cost, markets vacant, the entrant occupies these. Then since the entrant's captive area has increased in size relatively to the duopoly area, the entrant will want to charge higher prices. But to in order to raise prices the entrant can choose to not enter some markets where he would have competed otherwise.

As is shown in the appendix, in equilibrium this effect is taken to the extreme: The incumbent leaves a large high-cost area to the entrant, who in turn does not enter into any market already occupied by the incumbent. Therefore in equilibrium both firms are monopolists and set price $\bar{p}$. At face value, this avoidance of competition is similar to the case without any UP constraints, but here the logic is different: Without UP constraints the entrant does not enter because the direct effect would be losses in the markets he enters. In the equilibrium under UP constraints on both firms, the direct effect of entry would be a positive profit in the new local market, but the accompanying negative effect on the price level in all captive markets

\footnotetext{
${ }^{7}$ For the sake of completeness we remark that if a UP constraint is imposed on the entrant only, it can easily be seen that the outcome is identical to the one with no UP constraint, i.e. monopoly by the incumbent. The reason is again that the incumbent preempts on all of $X^{m}$, and that the entrant would make zero gross profits in duopoly areas.
} 
is stronger. This is a purely strategical effect caused by the entrant's UP constraint.

Proposition 4 If UP constraints are imposed on both firms, total coverage will be equal to the monopoly coverage $X^{m}$, with the incumbent serving the "cheaper" half of the market $X_{I}^{I E}=\left[0, x^{m} / 2\right]$, and the entrant the rest $X_{E}^{I E}=$ $\left(x^{m} / 2, x^{m}\right]$. Both firms do not compete in any market, equilibrium prices therefore are equal to $\bar{p}$ everywhere.

In other words, the equilibrium allocation is exactly the same as under monopoly (even capacity investments are exactly the same), only the identity of the firm serving the high-cost market changes. In fact, allowing entry under UP on both firms can be seen as simply transferring profits from the incumbent to the entrant, without any benefits to consumers.

This result means that imposing the UP constraint on both incumbent and entrant forgoes the (static) benefits created by competition, which are lower prices for consumers. Of course a low price cap also reduces prices in equilibrium, but has the negative effect of reducing total coverage as well. In addition, in the equilibrium with the UP constraint only on the incumbent, equilibrium prices are (stochastically) lower than the price cap, without the negative effects on coverage. Note that the captive consumers of the entrant do not gain from the imposition of the UP constraint, contrary to the captive consumers of the incumbent in Proposition 3, since they are charged the highest price $\bar{p}$ in either case.

To summarize, we have shown in this section that any expected benefits from allowing entry only materialize if a uniform pricing constraint is imposed solely on the incumbent firm, while the other options of not imposing any UP constraints, or imposing them on both firms, lead to the same allocation as under monopoly.

\subsection{Unbundling}

One may think that the results of Propositions 3 and 4 are caused by the fact that the entrant is forced to install own capacity. This makes entry expensive, and the fixed cost of entry may not be recoverable under competition. Under unbundling, though, the regulator obliges the incumbent to rent out capacity in the network where the entrant chooses to enter. In these areas both firms will compete as before, while the entrant does not support the fixed cost, and his marginal costs are equal to the rental price.

In general the price of line rental will above the marginal costs of the incumbent to compensate him for the fixed costs incurred and profits lost 
due to competition. For simplicity we will make here the extreme assumption that the rental price is equal to marginal costs. Since this rental price is most favorable to the entrant, the advantages of unbundling should be most visible in this case. ${ }^{8}$

We will now find the statements corresponding to Propositions 2, 3 and 4 above. First assume that no UP constraint is imposed on either firm. In the third stage both firms make zero profits wherever they compete, thus in the second stage firm 2 is totally indifferent between entering or not. Since in this case equilibrium is indeterminate, we assume that the entrant has an (arbitrarily small) cost of starting business, and will not enter if he makes zero profits everywhere. Under this assumption it is clear that the findings of Proposition 2 are reproduced, i.e. the entrant will not enter and the incumbent remains monopolist on $X^{m}$.

Assume now that the UP constraint is imposed on the incumbent only. Then it is clear that entry will be more pronounced than in the case without unbundling, because the entrant does not have to cover any fixed costs of capacity. Still, he will not enter everywhere, for the same strategic reasons pointed out above: There is a trade-off between the profits in an additional location and the loss in profits due to higher prices in all locations. Proposition 3 becomes:

Proposition 5 With unbundling, if a UP constraint is imposed on the incumbent only, the incumbent chooses the coverage $X_{I}^{I}=\left[0, x^{I}\right]$ with $x^{I}=$ $x^{I}=\frac{1}{2} x^{m}$. The entrant competes with the incumbent on $X_{E D}^{I}=\left[0, x^{D}\right]$ with $x^{D}=\frac{1}{4} x^{m}$, while serving the area $X_{E M}^{I}=\left(x^{I}, x^{m}\right]$ as a monopolist. Total coverage is equal to $X^{m}$. Expected gross profits are

$$
\begin{aligned}
\Pi_{I}^{I} & =\left(x^{I}-x^{D}\right) \bar{\pi}=\frac{1}{4} \frac{\bar{\pi}^{2}}{F}, \\
\Pi_{E}^{I} & =\left(\frac{x^{D}\left(x^{I}-x^{D}\right)}{x^{I}}+\left(x^{m}-x^{I}\right)\right) \bar{\pi}=\frac{5}{8} \frac{\bar{\pi}^{2}}{F},
\end{aligned}
$$

while expected total profits are

$$
\begin{aligned}
& \hat{\Pi}_{I}^{I}=\Pi_{I}^{I}-\frac{1}{2} F\left(x^{I}\right)^{2}=\frac{1}{8} \frac{\bar{\pi}^{2}}{F}=\frac{1}{4} \Pi^{m} \\
& \hat{\Pi}_{E}^{I}=\Pi_{E}^{I}-\frac{1}{2} F\left(\left(x^{m}\right)^{2}-\left(x^{I}\right)^{2}\right)=\frac{1}{2} \Pi^{m}
\end{aligned}
$$

\footnotetext{
${ }^{8}$ With a higher rental price firms have different marginal costs, which makes the analysis of the pricing equilibrium considerably more complex (details are available from the author).
} 
Consumers are charged $p_{D}=\min \left\{p_{I}, p_{E}\right\}$ on $X_{E D}^{I}, p_{I}$ on $X_{I}^{I} \backslash X_{E D}^{I}$, and $\bar{p}$ with certainty on $X_{E M}^{I}$. In terms of first-order stochastic dominance, we have $p_{D}<p_{I}<\bar{p}$ (but $p_{I}=\bar{p}$ with probability $1 / 2$ ).

We find that qualitatively the results have not changed, apart from the fact that there is no duplication of capacity. Still, coverage by the incumbent is smaller than without unbundling, and the duopoly area and the entrant's monopoly area are larger. Total profits of the entrant now are larger than the incumbent's, and prices are lower (stochastically) because $P_{I}$ is smaller and both $F_{I}\left(p_{I}\right)$ and $F_{E}\left(p_{E}\right)$ are decreasing in $P_{I}$. The only customers that are worse off are the ones in the interval $\left(x^{m} / 2,(\sqrt{3}-1) x^{m}\right]$, which are now served by the entrant at price $\bar{p}$, instead by the incumbent at a lower price.

Finally, consider the case where UP is imposed on both firms. We obtain:

Proposition 6 With unbundling, if UP constraints are imposed on both firms, total coverage will be equal to the monopoly coverage $X^{m}$, with the incumbent serving the "cheaper" half of the market $X_{I}^{I E}=\left[0, x^{m} / 2\right]$, and the entrant the rest $X_{E}^{I E}=\left(x^{m} / 2, x^{m}\right]$. Both firms do not compete in any market, equilibrium prices therefore are equal to $\bar{p}$ everywhere.

Maybe surprisingly, this outcome is identical to the one in Proposition 4, and the entrant rather prefers to install own capacity than to make use of unbundled lines. Globally the underlying economic mechanisms are not the same as in Proposition 4 since unbundling changes firms' payoffs, but at the margin they are: The fixed cost of entering the cheapest duopoly market at $x=0$ is zero, just as under unbundling, therefore the marginal decision to compete in the first duopoly market is the same. If the incumbent can prevent the entrant from competing without unbundling, then he can do so with unbundling as well: The entrant's incentives to avoid competition in order to make profits in captive areas are identical. Therefore, if the entrant is bound by a UP constraint, competition cannot be created even if he is freed of the need to install his own capacity.

\subsection{Large installed capacity}

In the previous two sections we assumed that the incumbent's installed capacity was so small that it was below the coverages chosen in equilibrium. Now we assume that before entry, and for historical reasons, the incumbent has a coverage of $X^{h}=\left[0, x^{h}\right]$, where $x^{h}$ may even be larger than the 
monopoly coverage $x^{m}$. After entry the incumbent must serve this area (even if it involves losses), and may be obliged to rent out lines to the entrant. ${ }^{9}$

If no UP constraints are imposed, installed capacity has no effect on entry with or without unbundling: The entrant's profits will remain zero. This is different if UP is imposed on the incumbent, or on both firms. In both cases, a larger coverage makes the incumbent price less aggressively, which facilitates entry. Furthermore, the incumbent now cannot choose to be small and leave the high-cost areas to the entrant. Therefore we expect to see that more entry will occur in markets where both firms will compete. The proof of the following proposition is straight-forward and based on the entrant's coverage best responses derived in the proofs of Propositions 3, 4, 5, 6, and the fact that the incumbent will choose the installed capacity or the previous equilibrium, whichever is smaller.

Proposition 7 Assume the incumbent has installed capacity $x^{h}$ larger than the equilibrium values in Propositions 3, 4, 5 and 6. Then in equilibrium the incumbent will not install new capacity. The entrant's choices are:

1. With UP only on the incumbent, the entrant will occupy the high-cost areas $\left(x^{h}, x^{m}\right]$ if $x^{h}<x^{m}$, and

(a) without unbundling, the entrant enters in $\left[0, x^{h} /\left(2+x^{h} / x^{m}\right)\right]$.

(b) under unbundling, the entrant enters in $\left[0, x^{h} / 2\right]$.

2. With UP on both firms,

(a) without unbundling, if $x^{h}<\frac{1}{2}(\sqrt{5}-1) x^{m}$ the entrant serves the high-cost area $\left(x^{h}, x^{E}\right]$ and the duopoly area $\left[0, x^{D}\right]$ with

$$
\begin{aligned}
x^{D} & =\frac{\left(2 x^{h}-x^{m}\right) x^{m} x^{h}}{2 x^{m} x^{h}-\left(x^{m}\right)^{2}+\left(x^{h}\right)^{2}}, \\
x^{E} & =\frac{x^{m}\left(x^{h}\right)^{2}}{2 x^{m} x^{h}-\left(x^{m}\right)^{2}+\left(x^{h}\right)^{2}} .
\end{aligned}
$$

If $x^{h} \geq \frac{1}{2}(\sqrt{5}-1) x^{m}$ then the entrant only enters in the duopoly area $\left[0, x^{h} /\left(2+x^{h} / x^{m}\right)\right]$ as under 1 (a) above, and high-cost areas are not served.

\footnotetext{
${ }^{9}$ An alternative interpretation is that $x^{h}$ describes a requirement of minimum coverage imposed by the regulator on the incumbent, as in Valletti et al. (2002). The results derived below show that this requirement counters some of the nefarious competitive effects described in the last sections.
} 
(b) under unbundling, high-cost areas will not be served either, and entry occurs in $\left[0, x^{h} / 2\right]$ as under $1(b)$.

Therefore the larger the installed capacity, the larger will be the scale of entry resulting in competition, but high-cost areas may suffer. In particular, when the incumbent is large, imposing UP on both firms will not hinder the creation of competition, but high-cost areas may not be served at all.

\section{Welfare}

Until now we have mainly argued in terms of coverage and equilibrium prices. As we have seen, under the assumptions of homogeneous services and identical technology total equilibrium coverage remains the same in all cases, while equilibrium prices are below the maximum price $\bar{p}$ (monopoly price or price cap) if the uniform pricing constraint is solely imposed on the incumbent. This feature of the model simplifies welfare comparisons considerably.

With total welfare defined as the sum of consumer surplus and firms' net profits, total welfare under the regimes that lead to the monopoly allocation is the same, since the same consumers are served, at the same price, and since the same capacity is installed. Only the distribution of profits between incumbent and entrant changes while the sum of profits is constant. Total welfare in these cases (monopoly, no UP constraint, UP on both with or without unbundling) is:

$$
W^{m}=W^{n}=W^{I E}=S(\bar{p}) x^{m}+\bar{\pi} x^{m}-\frac{1}{2} F\left(x^{m}\right)^{2},
$$

where consumer welfare at price $p$ (gross of expenses) is defined as $S(p)=$ $\int_{p}^{\hat{p}} Q(s) d s$.

When UP is imposed only on the incumbent and lines are not unbundled, total expected welfare can be expressed as

$$
\begin{aligned}
W & =E\left[S\left(\min \left\{p_{I}, p_{E}\right\}\right)\right] x^{D}+E\left[S\left(p_{I}\right)\right]\left(x^{I}-x^{D}\right)+S(\bar{p})\left(x^{m}-x^{I}\right)(8) \\
& +\Pi_{I}+\Pi_{E}-\frac{1}{2} F\left(x^{m}\right)^{2}-\frac{1}{2} F\left(x^{D}\right)^{2} .
\end{aligned}
$$

Here fixed costs are duplicated, leading to the last term, while prices are lower. The expected surplus terms are computed in the following lemma:

Lemma 2: We have

$$
\begin{aligned}
E\left[S\left(p_{I}\right)\right] & =S\left(p_{0}\right)-P_{I} \bar{\pi} \int_{p_{0}}^{\bar{p}-} \frac{1}{p-c} d p \\
E\left[S\left(\min \left\{p_{I}, p_{E}\right\}\right)\right] & =S\left(p_{0}\right)-\frac{P_{I}^{2}}{1-P_{I}} \bar{\pi} \int_{p_{0}}^{\bar{p}}\left(\frac{\bar{\pi}}{R(p)}-1\right) \frac{1}{p-c} d p .
\end{aligned}
$$


This leads to the following result:

Proposition 8 Total welfare with a UP constraint on the incumbent and no unbundling is higher than under the monopoly benchmark if and only if

$$
S\left(p_{0}\right)-S(\bar{p}) \geq \frac{1}{4}(\sqrt{3}-1) \bar{\pi}+\left(3-\frac{3}{2} \sqrt{3}\right) \bar{\pi}^{2} \int_{p_{0}}^{\bar{p}} \frac{1}{Q(p)(p-c)^{2}} d p
$$

where $p_{0}$ is defined through $R\left(p_{0}\right)=\bar{\pi} \sqrt{3} /(1+\sqrt{3})$.

Condition (9) does not depend on the value of $F$, i.e. on whether the fixed costs of entry are low or high, while it does depend on the values of $\bar{p}, c$ and the form of the demand function $Q(p)$. The effect of any of these is ambiguous and possible non-monotone. ${ }^{10}$ It can be shown that for linear demand, $Q(p)=1-p$, welfare $W^{I}$ is larger than $W^{m}$ if $\bar{p}-c$ is large enough, and smaller if $\bar{p}$ is close to $c .{ }^{11}$ In this setting imposing the UP constraint on the incumbent (but not on the entrant) improves total welfare, but only if the price cap is high enough. In other words, if a low price-cap is in place anyway then

With unbundled lines total welfare $W^{U}$ is unambiguously higher than in the benchmark monopoly case (and UP on both firms) because prices are lower while total coverage is the same and capacity is not duplicated: $W^{U}>$ $W^{m}$. Yet, the comparison of total welfare with and without unbundling is not trivial: As we have seen above, the duopoly area under unbundling is larger, and prices in cheap locations are lower; still, some consumers are paying higher prices to the entrant. The total effect is ambiguous, even though it is likely that welfare will be higher under unbundling. In fact, with the above linear demand function we have $W^{U}>W^{I}$ always: Unbundling is better.

Finally, we consider the situation under a high installed capacity, or, as remarked above, a minimum coverage requirement imposed on the incumbent. For simplicity we will assume $x^{h} \geq \frac{1}{2}(\sqrt{5}-1) x^{m} \approx 0.618 x^{m}$, so that by Proposition 7 the entrant does not serve any high-cost areas if UP is imposed on him. Then no matter whether UP is imposed on both firms or just on the incumbent, both firms compete on $\left[0, x^{h} /\left(2+x^{h} / x^{m}\right)\right]$ with capacity-based entry, and $\left[0, x^{h} / 2\right]$ under unbundling. Since here total welfare on $\left[0, x^{h}\right]$ does not change if UP is imposed on the entrant, the welfare comparison between UP on both or just on the incumbent depends on whether $x^{h} \geq x^{m}$

\footnotetext{
${ }^{10}$ Still, it is easy to see that any replication of demand, such as replacing $Q(p)$ by $\lambda Q(p)$ for $\lambda>0$, does not change the inequality since $\lambda$ cancels out.

${ }^{11}$ Details are available from the author on request.
} 
or not. In the latter case the high-cost areas $\left[x^{h}, x^{m}\right]$ remain unserved even though total welfare resulting from this area would be positive, while in the former case welfare remains the same (and the imposition of UP has no effects at all). Therefore imposing UP on both firms lowers total welfare, or at best has no effects.

As concerns the comparison between unbundling and capacity-based entry, it is easy to see from the last paragraph that firms compete on a larger area under unbundling. This leads to more competition and lower prices. Since the countervailing effects of lower incumbent equilibrium coverage are absent, the welfare comparison is clear: Unbundling leads to higher total welfare.

\section{Conclusions}

We have considered a model of entry into a series of markets with differing cost of entry. These markets are subject to regulation such as price caps, uniform pricing constraints, and coverage constraints.

We have shown that consumer welfare may increase if a uniform pricing constraint is imposed on the incumbent firm, since the resulting price umbrella makes entry possible and gives enough incentives to an entrant firm to actually compete with the incumbent. These incentives are increased if the entrant can rent unbundled lines instead of installing own capacity, which leads to more entry and lower prices, while the downside is that less customers may benefit from competition.

Our strongest finding is that imposing uniform pricing constraints on both incumbent and entrant is undesirable. If installed capacity is small, the incumbent chooses to remain small and the entrant will not enter any markets already occupied by the incumbent, be there unbundling or not. Rather, the entrant concentrates on his own captive markets. In this case the equilibrium coverage and prices are identical to the monopoly allocation (This result is independent of whether a price cap is imposed or not). Furthermore, if installed capacity (or mandated coverage) is large, then competitive entry does occur in low-cost markets, but high-cost markets may not be served.

As concerns total welfare, if the uniform pricing constraint is imposed only on the incumbent and there is no unbundling, it can be higher or lower than under the monopoly allocation due to the duplication of capacity. We give an example where welfare is higher if the (given) price cap is high, and lower if the price cap is close to marginal cost.

Unbundling and a uniform pricing constraint on the incumbent lead to higher welfare than under monopoly precisely since capacities are not du- 
plicated and prices are lower. Still, the comparison between capacity-based entry and unbundling is not clear-cut since in the latter case almost a quarter of served customers pay higher prices because they are served only by the entrant. Nevertheless, in the previously-mentioned example total welfare is always higher under unbundling.

Future research will deal with some important questions that we have not yet touched upon: So far we have only considered static efficiency, while we have neglected dynamic efficiency in the sense of investments in new technology. There are (at least) two good reasons to investigate the latter: First, telecommunications are a field where technology is changing rapidly. Second, entry as such can be seen as a dynamic phenomenon, and one can ask simple questions such as: How would be incumbent invest under unbundling? Would the entrant make additional investments to be able to enter with a better product or lower costs? The answer to these questions will certainly depend on the regulatory framework.

A second question that we have left out so far is the question of interconnection and its regulation. If enough rents are created through interconnection charges, the incumbent may be willing to tolerate some competition even if he could in theory preempt the entrant.

\section{References}

[1] Anton, James J., Vander Weide, James H., and Vettas, Nikolaos (2002). "Entry Auctions and Strategic Behavior under Cross-Market Price Constraints". International Journal of Industrial Organization, 20(5):611-29.

[2] Armstrong, Mark and Vickers, John (1993). "Price Discrimination, Competition and Regulation". The Journal of Industrial Economics, 41(4):335359.

[3] Choné, Philippe, Flochel, Laurent, and Perrot, Anne (2000). "Universal Service Obligations and Competition". Information Economics and Policy, 12(3):249-259.

[4] Crandall, Robert W. and Waverman, Leonard (2000). Who Pays for Universal Service: When Telephone Subsidies Become Transparent. Brookings Institution Press, Washington DC.

[5] Laffont, Jean-Jaques and Tirole, Jean (2000). Competition in Telecommunications. Cambridge, MA: MIT Press. 
[6] Milton L. Mueller, Jr. (1997). Universal Service: Competition, Interconnection, and Monopoly in the Making of the American Telephone System. Cambridge, MA: MIT Press and AEI Press.

[7] Valletti, Tommaso M., Hoernig, Steffen H., and Barros, Pedro P. (2002). "Universal Service and Entry: The Role of Uniform Pricing and Coverage Constraints". Journal of Regulatory Economics, 21(2):169-90. 


\section{Appendix}

\section{Proof of Lemma 1:}

Assume that firm $i(i=1,2)$ sets prices according to a distribution function $F_{i}(p)$ with support $\left[\underline{s}_{i}, \bar{s}_{i}\right] \subset[0, \bar{p}]$, possibly with an atom at $\bar{s}_{i}$. Given these distributions, firm $i$ 's expected profits for any price $p \in\left[\underline{s}_{i}, \bar{s}_{i}\right]$ are

$$
\Pi_{i}=R(p)\left(D\left(1-F_{j}(p)\right)+m_{i}\right) \geq m_{i} \bar{\pi} .
$$

Firm $i$ makes profits $R(p)$ in each captive market, while obtaining positive sales in the competitive market only with probability $P\left(p_{j}>p\right)=1-F_{j}(p)$. In equilibrium this payoff must be at least as large as the maximum payoff that firm $i$ can achieve by just serving its captive markets, $m_{i} \bar{\pi}$.

We can solve for $F_{j}$ to obtain

$$
F_{j}(p)=\frac{D+m_{i}}{D}-\frac{\Pi_{i}}{D R(p)}
$$

which is a continuous function on $\left(\underline{s}_{i}, \bar{s}_{i}\right)$.

We now establish the lower limit of the distributions. In equilibrium there can be no atom at $\underline{s}_{i}>0$ since the other firm would underbid this price with positive probability. Also, we argue that $\underline{s}_{1}=\underline{s}_{2}=p_{0}$. Indeed, if one firm chooses a price smaller than the lowest price of the other firm it does not raise its probability of gaining the market (which is 1 in both cases), while decreasing its payoff. Solving $F_{j}\left(p_{0}\right)=0$ for $j=1,2$ leads to

$$
R\left(p_{0}\right)=\frac{\Pi_{1}}{D+m_{1}}=\frac{\Pi_{2}}{D+m_{2}},
$$

and

$$
F_{1}(p)=\frac{D+m_{2}}{D+m_{1}} F_{2}(p) \leq F_{2}(p),
$$

i.e. firm 2 (stochastically) charges lower prices than firm 1.

Now consider $\bar{s}_{2}$. First we assume that there is no atom at this price, that is, $P_{2}\left(p=\bar{s}_{2}\right)=0$ or $\lim _{p \rightarrow \bar{s}_{2}} F_{2}(p)=1$, leading to

$$
m_{1} R\left(\bar{s}_{2}\right)=\Pi_{1} \geq m_{1} \bar{\pi} .
$$

This is only possible with both $\bar{s}_{2}=\bar{p}$ and $\Pi_{1}=m_{1} \bar{\pi}$ since $R(p) \leq \bar{\pi}$ for all $p \leq \bar{p}$. If on the other hand there is an atom, $P_{2}\left(p=\bar{s}_{2}\right)>0$, because of $\lim _{p \rightarrow \bar{s}_{2}} F_{1}(p)<\lim _{p \rightarrow \bar{s}_{2}} F_{2}(p)<1$, firm 1 either has $P_{1}\left(p=\bar{s}_{2}\right)>0$ or uses even higher prices with positive probability. The former case cannot 
be an equilibrium because both firms would choose the price with positive probability, and, having to share the market, would make strictly less profits than if they were playing a price just below. The latter case also cannot be an equilibrium because then firm 2 would gain by using higher prices as well.

We conclude that $\bar{s}_{2}=\bar{p}, \Pi_{1}=m_{1} \bar{\pi}$ and

$$
\begin{aligned}
\Pi_{2} & =\frac{D+m_{2}}{D+m_{1}} \Pi_{1}=\frac{D+m_{2}}{D+m_{1}} m_{1} \bar{\pi} \\
F_{1}(p) & =\frac{D+m_{2}}{D}\left(1-\frac{m_{1}}{D+m_{1}} \frac{\bar{\pi}}{R(p)}\right), \\
F_{2}(p) & =\frac{D+m_{1}}{D}\left(1-\frac{m_{1}}{D+m_{1}} \frac{\bar{\pi}}{R(p)}\right) .
\end{aligned}
$$

It follows also that $s_{1}=\bar{p}$ and that firm 1 plays the maximum price with probability

$$
P_{1}(p=\bar{p})=\frac{m_{1}-m_{2}}{D+m_{1}}
$$

\section{Proof of Proposition 3:}

Assume that in the first stage the incumbent has decided where to enter and where not, leading to a total coverage of $X$. Let $X_{0}=[0, \sup X]$, and for any $x \in X_{0}$ let $v(x)$ be the measure of the area in $[0, x]$ that the incumbent has left vacant. Obviously $0 \leq v(x) \leq x$, and $v(x)$ is nondecreasing in $x$ and differentiable almost everywhere.

As discussed in the text, the entrant will occupy any vacant local market at position $x \leq x^{m}$, therefore we will now clarify in which markets he will compete with the incumbent. Assuming that the entrant has entered on $[0, x]$, he competes with the incumbent on an area of size $D=x-v(x)$, and his profits from the duopoly area are, following (4),

$$
\pi_{E}=\frac{(x-v(x))(|X|-(x-v(x)))}{|X|} \bar{\pi}+v(x) \bar{\pi}-\frac{1}{2} F x^{2} .
$$

At the optimal choice of $x \in X_{0}$ the derivative of this expression with respect to $x$ must be non-negative:

$$
\pi_{E}=\frac{\left(1-v^{\prime}(x)\right)(|X|-2(x-v(x)))}{|X|} \bar{\pi}+v^{\prime}(x) \bar{\pi}-F x \geq 0
$$


If $x$ is already occupied by the incumbent, then $v^{\prime}(x)=0$ and

$$
\frac{|X|}{x^{m}} x+2(x-v(x)) \leq|X| .
$$

The left-hand side is increasing in $x$, therefore this condition establishes an upper limit $x(|X|, v)$ on the duopoly area. This upper limit is increasing in $|X|$ (since $x<x^{m}$ ), and also increasing in $v$ : An increase in $v(x)$ for a given $x$ relaxes the constraint, and $x$ can be raised. Therefore, there is no strategic gain for the incumbent to leave some of the cheap markets vacant, on the contrary, this makes the entrant even more aggressive.

Thus in the first stage of the game the incumbent enters on an interval $X^{I}=\left[0, x^{I}\right]$, resulting in $v(x)=0$ for $x \leq x^{I}$. From (13) we can then determine that the entrant enters and competes on the area $X_{E D}^{I}=\left[0, x^{D}\right]$ where $\left(x^{m}=\bar{\pi} / F\right)$

$$
x^{D}=\frac{x^{I}}{2+x^{I} / x^{m}}
$$

leaving the incumbent with profits

$$
\hat{\Pi}_{I}^{I}=x^{I} \frac{x^{m}+x^{I}}{2 x^{m}+x^{I}} \bar{\pi}-\frac{1}{2} F\left(x^{I}\right)^{2} .
$$

These obtain their maximum at $x^{I}=(\sqrt{3}-1) x^{m}$, leading to $x^{D}=(2-\sqrt{3}) x^{m}$.

Finally, the equilibrium distributions of prices are obtained from $D=x^{D}$, $M_{I}=x^{I}-x^{D}$ and $M_{E}=0$ in (4), with

$$
\begin{aligned}
F_{I}\left(p_{I}\right) & =1-P_{I} \frac{\bar{\pi}}{R\left(p_{I}\right)}, \\
P_{I}\left(p_{I}=\bar{p}\right) & =P_{I}=\frac{\sqrt{3}}{1+\sqrt{3}} \approx 0.634, \\
F_{E}\left(p_{E}\right) & =\frac{1}{1-P_{I}}\left(1-P_{I} \frac{\bar{\pi}}{R\left(p_{E}\right)}\right),
\end{aligned}
$$

where both $F_{I}$ and $F_{E}$ are defined on $p \in\left[p_{0}, \bar{p}\right)$ with $R\left(p_{0}\right)=P_{I} \bar{\pi}$. Expected profits are obtained by substituting these values and simplifying.

\section{Proof of Proposition 4:}

In the first stage of the game the incumbent chooses to serve an area $\left[0, x^{I}\right]$, expecting the entrant to occupy some part of it and some area above $x^{I}$. It is easily seen that with a UP constraint on the entrant there is a strategic reason for the incumbent to leave a captive (high-cost) area for 
the entrant, and that the incumbent chooses to only leave high-cost markets vacant.

Given $x^{I}$, the entrant decides to compete on $\left[0, x^{D}\right]$ and occupy captive markets $\left(x^{I}, x^{E}\right]$, with $0 \leq x^{D} \leq x^{I} \leq x^{E}$. His payoffs are, if $x^{E}-x^{I} \leq$ $x^{I}-x^{D}$ or $x^{E}+x^{D} \leq 2 x^{I}$

$$
\hat{\Pi}_{E}^{I E}=\frac{\left(x^{D}+x^{E}-x^{I}\right)\left(x^{I}-x^{D}\right)}{x^{I}} \bar{\pi}-\frac{1}{2} F\left(\left(x^{D}\right)^{2}+\left(x^{E}\right)^{2}-\left(x^{I}\right)^{2}\right),
$$

and first derivatives are

$$
\begin{aligned}
\frac{d}{d x^{D}} \hat{\Pi}_{E}^{I E} & =\frac{2 x^{I}-2 x^{D}-x^{E}}{x^{I}} \bar{\pi}-F x^{D}, \\
\frac{d}{d x^{E}} \hat{\Pi}_{E}^{I E} & =\frac{x^{I}-x^{D}}{x^{I}} \bar{\pi}-F x^{E} \leq 0
\end{aligned}
$$

which must be equal to zero if $x^{D} \in\left(0, x^{I}\right)$, or $x^{E}>x^{I}$, respectively. First we notice that at $x^{D}=x^{I}$ we must have $d \hat{\Pi}_{E}^{I E} / d x^{D} \geq 0$, which cannot be true. Therefore we must have $x^{D}<x^{I}$. Second, $x^{D}=0$ is a solution if and only if $x^{I} \leq x^{m} / 2$, with $x^{E}=x^{m}$. Third, $x^{E}=x^{I}$ is a solution if and only if $x^{I} \geq \frac{1}{2}(\sqrt{5}-1) x^{m}$, with $x^{D}=x^{I} /\left(2+x^{I} / x^{m}\right)$. Finally, at an interior solution, we have $x^{m} / 2<x^{I}<\frac{1}{2}(\sqrt{5}-1) x^{m}$ and

$$
\begin{aligned}
x^{D} & =\frac{\left(2 x^{I}-x^{m}\right) x^{m} x^{I}}{2 x^{m} x^{I}-\left(x^{m}\right)^{2}+\left(x^{I}\right)^{2}} \\
x^{E} & =\frac{x^{m}\left(x^{I}\right)^{2}}{2 x^{m} x^{I}-\left(x^{m}\right)^{2}+\left(x^{I}\right)^{2}} .
\end{aligned}
$$

The profits of the incumbent are therefore

$$
\begin{aligned}
\hat{\Pi}_{I}^{I E}= & \left\{\begin{array}{ccc}
x^{I} \bar{\pi} & \text { if } & x^{I} \leq x^{m} / 2 \\
\left(x^{I}-\frac{\left(2 x^{I}-x^{m}\right) x^{m} x^{I}}{2 x^{m} x^{I}-\left(x^{m}\right)^{2}+\left(x^{I}\right)^{2}}\right) \bar{\pi} & \text { if } & x^{m} / 2<x^{I}<\frac{1}{2}(\sqrt{5}-1) x^{m} \\
\left(x^{I}-\frac{x^{I}}{2+x^{I} / x^{m}}\right) \bar{\pi} & \text { if } & x^{I} \geq \frac{1}{2}(\sqrt{5}-1) x^{m}
\end{array}\right. \\
& -\frac{1}{2} F\left(x^{I}\right)^{2} .
\end{aligned}
$$

Profits are continuous, increasing on the first segment, and decreasing on the second and third one. Therefore the maximum is attained at $x^{I}=x^{m} / 2$, where the entrant chooses $x^{D}=0$ and $x^{E}=x^{m}$.

\section{Proof of Proposition 5:}


Assume the incumbent covers $\left[0, x^{I}\right]$ and the entrant $\left[0, x^{E}\right]$. From (4) the entrant's gross profits are

$$
\hat{\Pi}_{E}^{I}=\frac{x^{D}\left(x^{I}-x^{D}\right)}{x^{I}} \bar{\pi}+\left(x^{E}-x^{I}\right) \bar{\pi}-\frac{1}{2} F\left(\left(x^{E}\right)^{2}-\left(x^{I}\right)^{2}\right),
$$

which are maximized over $x^{D} \in\left[0, x^{I}\right]$ and $x^{E} \geq x^{I}$. The optimal choices are $x^{D}=x^{I} / 2$ and $x^{E}=\max \left\{x^{m}, x^{I}\right\}$. Gross profits of the incumbent thus are

$$
\hat{\Pi}_{I}^{I}=\left(x^{I}-x^{D}\right) \bar{\pi}-\frac{1}{2} F\left(x^{I}\right)^{2}=\frac{1}{2} x^{I} \bar{\pi}-\frac{1}{2} F\left(x^{I}\right)^{2},
$$

with maximizers $x^{I}=x^{m} / 2$ and $x^{E}=x^{m} / 4$. The distributions of prices, and expected profits, are derived as in Proposition 3, with

$$
\begin{aligned}
F_{I}\left(p_{I}\right) & =1-\frac{1}{2} \frac{\bar{\pi}}{R\left(p_{I}\right)}, \\
P_{I}\left(p_{I}=\bar{p}\right) & =P_{I}=\frac{1}{2}, \\
F_{E}\left(p_{E}\right) & =2\left(1-\frac{1}{2} \frac{\bar{\pi}}{R\left(p_{E}\right)}\right),
\end{aligned}
$$

where both $F_{I}$ and $F_{E}$ are defined on $p \in\left[p_{0}, \bar{p}\right)$ with $R\left(p_{0}\right)=\bar{\pi} / 2$.

\section{Proof of Proposition 6:}

Assume that the incumbent covers the area $\left[0, x^{I}\right]$ and expects entry on $\left[0, x^{D}\right]$; the entrant also has captive markets $\left(x^{I}, x^{E}\right]$. Since now prices are related, the entrant's gross profits are given by (5), with total profits

$$
\hat{\Pi}_{E}^{I E}=\frac{\left(x^{D}+x^{E}-x^{I}\right)\left(x^{I}-x^{D}\right)}{x^{I}} \bar{\pi}-\frac{1}{2} F\left(\left(x^{E}\right)^{2}-\left(x^{I}\right)^{2}\right) .
$$

First order conditions are

$$
\begin{aligned}
\frac{d}{d x^{D}} \hat{\Pi}_{E}^{I E} & =\frac{2 x^{I}-2 x^{D}-x^{E}}{x^{I}} \bar{\pi}(\leq,=, \geq) 0, \\
\frac{d}{d x^{E}} \hat{\Pi}_{E}^{I E} & =\frac{x^{I}-x^{D}}{x^{I}} \bar{\pi}-F x^{E} \leq 0
\end{aligned}
$$

depending on whether $x_{2}=0, x_{2} \in\left(0, x^{I}\right)$ or $x_{2}=x_{1}$. These conditions simplify to

$$
\begin{aligned}
2 x^{I}-2 x^{D}-x^{E}( & \leq,=, \geq) 0 \\
\left(x^{I}-x^{D}\right) x^{m}-x^{I} x^{E} & \leq 0 .
\end{aligned}
$$


Again, we have to look at various cases:

Case A: $x^{D}=x^{I}$ : It follows that $-x^{E} \geq 0$ or $x^{E} \leq 0$, leading to a contradiction.

Case B: $x^{D}=0$ : Here $2 x^{I}-x^{E} \leq 0$ and $x^{I}\left(x^{m}-x^{E}\right) \leq 0$. Therefore $x^{E}=x^{m}$, and from the former constraint we see that $x^{I} \leq x^{m} / 2$ is necessary for this case to obtain.

Case C: $x^{E}=x^{I}$ : Here $2 x^{I}-2 x^{D}-x^{I}=0$, with solution $x^{D}=x^{I} / 2$. The second condition then leads to $x^{I} \geq x^{m} / 2$.

Case D: both $x^{D}$ and $x^{E}$ are interior:

$$
2 x^{I}-2 x^{D}-x^{E}=0,\left(x^{I}-x^{D}\right) x^{m}-x^{I} x^{E}=0,
$$

with solution $x^{E}=0, x^{D}=x^{I}$, a contradiction.

Therefore total profits of the incumbent $\operatorname{are}^{12}$

$$
\hat{\Pi}_{I}^{I E}=\left\{\begin{array}{lll}
x^{I} x^{m}-\frac{1}{2}\left(x^{I}\right)^{2} & \text { if } & x^{I} \leq x^{m} / 2 \\
\frac{x^{I}}{2} x^{m}-\frac{1}{2}\left(x^{I}\right)^{2} & \text { if } & x^{I}>x^{m} / 2
\end{array} .\right.
$$

These are increasing on the first segment, and decreasing on the second, therefore obtain the maximum at $x^{I}=x^{m} / 2$, with $x^{D}=0$. Equilibrium payoffs are determined as above.

\section{Proof of Lemma 2:}

First consider $E\left[S\left(p_{I}\right)\right]$, and the price distributions from the proof of Proposition 3. Since $\lim _{p \rightarrow \bar{p}} F_{I}(p)=1-P_{I}<1$, we must be careful in writing down the expected value: The first term corresponds to choosing the price $\bar{p}$ with probability $P_{I}$, while the second term involves the other prices $p \in\left[p_{0}, \bar{p}\right):$

$$
\begin{aligned}
& E\left[S\left(p_{I}\right)\right]=\int_{p_{0}}^{\bar{p}} S(p) d F_{I}(p)=P_{I} S(\bar{p})+\int_{p_{0}}^{\bar{p}-} S(p) d F_{I}(p) \\
= & P_{I} S(\bar{p})+\left[-S(p)\left(1-F_{I}(p)\right)\right]_{p_{0}}^{\bar{p}-}-\int_{p_{0}}^{\bar{p}-} Q(p)\left(1-F_{I}(p)\right) d p \\
= & S\left(p_{0}\right)-\int_{p_{0}}^{\bar{p}-} Q(p)\left(1-F_{I}(p)\right) d p=S\left(p_{0}\right)-P_{I} \int_{p_{0}}^{\bar{p}-} Q(p) \frac{\bar{\pi}}{R(p)} d p \\
= & S\left(p_{0}\right)-P_{I} \bar{\pi} \int_{p_{0}}^{\bar{p}-} \frac{1}{p-c} d p .
\end{aligned}
$$

\footnotetext{
${ }^{12}$ Since at $x^{I}=x^{m} / 2$ the entrant is indifferent between the two scenarios, we assume that he chooses the first alternative, or that the incumbent approaches the equilibrium arbitrarily closely from below.
} 
Let us now turn to $E\left[S\left(\min \left\{p_{I}, p_{E}\right\}\right)\right]$ :

$$
\begin{aligned}
& E\left[S\left(\min \left\{p_{I}, p_{E}\right\}\right)\right] \\
= & \int_{p_{0}}^{\bar{p}} \int_{p_{0}}^{\bar{p}} S\left(\min \left\{p_{I}, p_{E}\right\}\right) d F_{E}\left(p_{E}\right) d F_{I}\left(p_{I}\right)+P_{I} \int_{p_{0}}^{\bar{p}} S(p) d F_{E}(p) \\
= & \int_{p_{0}}^{\bar{p}} \int_{p_{E}}^{\bar{p}} d F_{I}\left(p_{I}\right) S\left(p_{E}\right) d F_{E}\left(p_{E}\right)+\int_{p_{0}}^{\bar{p}} \int_{p_{I}}^{\bar{p}} d F_{E}\left(p_{E}\right) S\left(p_{I}\right) d F_{I}\left(p_{I}\right) \\
& +P_{I} \int_{p_{0}}^{\bar{p}} S(p) d F_{E}(p) \\
= & \int_{p_{0}}^{\bar{p}} S(p)\left(1-F_{I}(p)\right) d F_{E}(p)+\int_{p_{0}}^{\bar{p}} S(p)\left(1-F_{E}(p)\right) d F_{I}(p) \\
= & {\left[-S(p)\left(1-F_{E}(p)\right)\left(1-F_{I}(p)\right)\right]_{p_{0}}^{\bar{p}}-\int_{p_{0}}^{\bar{p}} Q(p)\left(1-F_{E}(p)\right)\left(1-F_{I}(p)\right) d p } \\
= & S\left(p_{0}\right)-\int_{p_{0}}^{\bar{p}} Q(p)\left(1-F_{E}(p)\right)\left(1-F_{I}(p)\right) d p .
\end{aligned}
$$

This simplifies to

$$
\begin{aligned}
& E\left[S\left(\min \left\{p_{I}, p_{E}\right\}\right)\right]=S\left(p_{0}\right)-\int_{p_{0}}^{\bar{p}} Q(p)\left(1-F_{E}(p)\right)\left(1-F_{I}(p)\right) d p \\
= & S\left(p_{0}\right)-\frac{P_{I}^{2}}{1-P_{I}} \bar{\pi} \int_{p_{0}}^{\bar{p}}\left(\frac{\bar{\pi}}{R(p)}-1\right) \frac{1}{p-c} d p .
\end{aligned}
$$

\section{Proof of Proposition 8:}

Using the equilibrium values given in Proposition $3, W^{I} \geq W^{m}$ if

$$
2 E\left[S\left(\min \left\{p_{I}, p_{E}\right\}\right)\right]+2 \sqrt{3} E\left[S\left(p_{I}\right)\right]-(2 \sqrt{3}+2) S(\bar{p})-\bar{\pi} \geq 0 .
$$

Here $F$ already cancels out. Substituting the expected values from above and simplifying leads to the result stated in the text. 